\title{
CONTRIBUTO PARA O ESTUDO DO RUMOR NAS ORGANIZAÇÕES
}

\section{Revisão e articulação de algumas perspectivas teóricas}

\author{
SANDRA MARINHO *
}

\section{RESUMO}

Pensar nos rumores fora da vida quotidiana e vê-los nas organizaçōes, enquanto forma de comunicação interna, não tem sido um caminho fácil. As consequências dos rumores são geralmente negativas; os rumores são, quase sempre, conotados de imediato com coscuvilhices; são rápidos, voláteis, enfim, difíceis de estudar.

As dificuldades em empreender estudos empíricos são fáceis de ver: poder acompanhá-los desde o início e observá-los passo a passo é um golpe de sorte, um rasgo de oportunidade, um "estar no local certo, no momento certo", o que sucede muito poucas vezes. Criá-los «laboratorialmente» resulta em perda de espontaneidade e introduz vícios no seu processo de transmissão. Lançá-los propositadamente em ambientes naturais levanta sérias questões éticas e incontornáveis.

Apesar destas dificuldades, o estudo dos rumores e dos seus efeitos nas organizações tem vindo a prosseguir, sob diversas perspectivas e orientações, contributos que tentamos articular nesta breve revisão bibliográfica.

"Saber é poder."

FRANCIS BACON

«... Os falsos boatos constituem o preço a pagar

pelos boatos com fundamento.»

JEAN-NOEL KAPFERER

* Assistente do Departamento de Ciências da Comunicaçāo da Universidade do Minho. E-mail: marinho@ics.uminho.pt 
De acordo com um Dicionário da Língua Portuguesa, um boato é «uma notícia que corre publicamente, mas não confirmada» e um rumor é definido como «um ruído confuso de vozes; sussurro; murmúrio; rebuliço; alvoroço; agitação; notícia que corre de boca em boca». Teobaldo de Andrade refere-se ao rumor nos seguintes termos:

«O rumor é tão importante que poderíamos mesmo falar em uma 'patologia das comunicações', isto é, uma ciência que estudasse as causas, os sintomas e a natureza dessa verdadeira doença que é a 'voz que corre'. O rumor é, em geral, a explanação de factos numa distorção intencional ou não da sua realidade. Essa distorção é, quase sempre, grosseira, mas nem por isso perde o seu valor. Ele difunde-se com grande velocidade, atingindo em pouco tempo os lugares mais distantes" (Andrade, 1993:111).

As definições apresentadas ilustram bem a forma como foi tratado o rumor, durante muito tempo: como um problema grave para os indivíduos e organizações, uma distorção grosseira da realidade, uma fonte de enganos. No entanto, nos últimos anos, alguns autores têm vindo a desenvolver estudos empíricos, com o objectivo de conhecer melhor este fenómeno de comunicação informal, identificando os seus padrões de proliferação, bem como possíveis formas de o prevenir e controlar, nomeadamente em ambientes organizacionais, onde os seus efeitos se podem revelar especialmente destrutivos.

\section{O rumor: evento de comunicação humana}

Antes de mais, impõem-se algumas considerações prévias, indispensáveis a um correcto enquadramento da questão que vamos abordar. Consideramos essencial integrar o fenómeno do rumor nos processos de comunicação informal que, por sua vez, podem desenrolar-se ao nível da organização, um dos contextos de realização dos actos de comunicação humana. Nāo queremos com isto transmitir a ideia de que concebemos o rumor ou boato enquanto "célula» isolada das actividades de comunicação formal e externa que, obviamente, influenciam os acontecimentos que se desenrolam no interior das organizações.

Mais ainda, temos em conta a natureza parcialmente coincidente dos diferentes contextos de comunicação humana, amplamente defendida por Thayer (1976). Se considerarmos que em cada organização há uma série de elementos que se organizam hierarquicamente, teremos em jogo, simultaneamente, indivíduos a processarem informação para si próprios (nível intrapessoal) e também um contexto de comunicação interpessoal, que representa todos os actos de comunicação entre duas ou mais pessoas. Para 
além destes, há ainda os elementos organizacionais, que são as cadeias que ligam grupos de indivíduos em organizações e ainda o nível tecnológico que se traduz nos "programas mecânicos, electrónicos ou de software para auxiliar no processo de manipulação da informação" (Thayer, 1976: 60).

Contudo, iremos referir-nos aos eventos de comunicação num contexto tipicamente organizacional, onde estão presentes as características próprias e definidoras da comunicação no seio dos grupos estruturados por regras e onde se realizam jogos de poder e de influência que determinam muitas das orientações da informação aí produzida. Vemos assim as organizações como «sistemas complexos predominantemente estruturados em torno de eventos de comunicação" (Littlejohn, 1982: 317), que são um factor estratégico fundamental, o que faz com que devam ser cuidadosamente planeados e controlados, de maneira a promover a transmissão de informação útil, da forma mais adequada e no momento oportuno, ao público específico a que se destinam. Comunicação organizacional é também ...

«...o processo através do qual membros de uma organização reúnem informação pertinente sobre esta e sobre as mudanças que ocorrem no seu interior e a fazem circular endógena e exogenamente. A comunicação permite às pessoas gerar e partilhar informações, que lhes dão capacidade de cooperar e de se organizarem" (Kreps, 1990).

São igualmente importantes, ao nível da comunicação interna, os conceitos de "macrorrede» ou «macronetwork», enquanto "padrão repetitivo de transmissão de informações entre grupos ou organizações» (Littlejohn, 1982: 316). Neste sentido, podem existir numa organização humana numerosas redes não formais, organizando os seus membros em grupos, ligados de várias maneiras para partilharem informação. Cada membro do grupo, por sua vez, agirá numa série de zonas, de acordo com a sua influência.

Não perdemos também de vista os pressupostos presentes nas definições de comunicação humana: trata-se de um campo multidisciplinar e multiteórico, que convoca contributos de várias outras disciplinas e ciências. Comunicar será assim tornar comum uma realidade, uma informação, uma ideia, um pensamento ou uma atitude, através de um qualquer meio efectivo. Como tal, exige a presença de um conjunto de elementos: um emissor ou fonte, um receptor ou destinatário, uma mensagem, um canal, uma situação ou circunstância e uma intenção, propósito ou necessidade. Ao receptor caberá determinar o sucesso de qualquer acto de comunicação, ao «levar em consideração» a informação transmitida pela fonte, o «fenómeno básico» que preside a qualquer acto de comunicação (Thayer, 1976). 


\section{A comunicação informal nas organizações: \\ a "grapevine» em acção}

O conceito de "grapevine», surgido durante a Guerra Civil Americana, traduz um sistema de comunicação informal coexistente com os canais formais. Na época, as linhas do telégrafo dos serviços secretos eram penduradas de árvore em árvore como uma vinha ("grapevine») e, em alguns casos, acabavam mesmo por nascer vinhas selvagens ao longo dos fios. Visto que as mensagens transmitidas eram, muitas vezes, incorrectas ou confusas, o que não é de admirar num cenário de guerra, sempre que surgia algum rumor dizia-se que provinha da «grapevine». O termo acabou por ser adoptado e, actualmente, é empregue para designar toda a comunicação informal, incluindo a que se desenrola nas organizações.

Embora os seus padrōes de proliferação sejam distintos, e até certo ponto imprevisíveis, a "grapevine» segue geralmente o padrão "cluster» (cacho):

«O empregado X diz a outros três ou quatro. Só um ou dois destes receptores irão passar adiante a informação e os que o fazem irão, geralmente, contar a mais que uma pessoa. Então, à medida que a informação vai 'envelhecendo' e que a proporção daqueles que tomam conhecimento dela aumenta, morre gradualmente, porque nem todos os que a recebem a repetem. Este tipo de rede é conhecida por cadeia em cacho ('cluster'), porque cada um dos elos da cadeia tende a informar um conjunto de pessoas, em vez de contar a uma só pessoa» (Newstrom \& Davis, 1997: 76).

Daqui, podemos deduzir que só um pequeno grupo de membros são comunicadores activos na ugrapevine». Newstrom \& Davis (1997) classificam-nos como "elementos de ligação». Na sua opinião, "a 'grapevine' é um produto da situação e não da pessoa», ou seja, numa situação favorável, qualquer pessoa pode tornar-se num elemento activo.

Há, no entanto, alguns factores que tendem a dinamizar a actividade deste sistema: estados de excitação e insegurança; envolvimento de sócios ou amigos; informação recente; procedimentos que coloquem as pessoas em contacto; trabalhos que permitam aos empregados conversar; trabalhos que dêem acesso a informação que possa interessar a outros; e, por fim, também a personalidade do comunicador (Newstrom \& Davis, 1997).

Baker \& Jones preocupam-se com o funcionamento da "grapevine» em situações de «disfuncionalidade organizacional»:

«As características disfuncionais nas organizações podem criar barreiras a uma comunicação aberta, aos níveis vertical e horizontal. Ironicamente, embora os líderes organizacionais normalmente digam que preferem os meios directos de comunicação, muitas vezes os funcionários dependem primordialmente da 'grapevine' para receber e enviar infor- 
mação. Embora em algumas organizações a 'grapevine' possa ser um meio fiável a válido para reunir informação, na maior parte das vezes não o é, principalmente quando o sistema desenvolveu alguma disfuncionalidade» (Baker \& Jones, 1996: 76).

Segundo estes autores, os indivíduos transferem para as organizações os seus "comportamentos baseados em necessidades" (Baker \& Jones, 1996: 76), adquiridas nas suas relações familiares. Estes comportamentos podem ser de vária ordem, mas estão geralmente associados a necessidades de controlo e de exercício de poder, para superar sentimentos de insegurança gerados por um sistema que os indivíduos percepcionam como sendo disfuncional. Trata-se de indivíduos preocupados essencialmente em atingir os seus objectivos emocionais:

«... estão mais preocupados em realizar as suas necessidades pessoais do que em atingir os objectivos estabelecidos para a organização, embora declarem que trabalham em consonância com os interesses da organização» (Baker \& Jones, 1996: 76).

As relaçōes estabelecidas por este tipo de indivíduos implicam normalmente comportamentos como: «... violação de fronteiras, quebra de confiança, conspirações de silêncio, controlos desnecessários, culpabilizações...» (Baker \& Jones, 1996: 76). Aliás, duas das características destes «sistemas disfuncionais» são precisamente a «falta de confiança e falta de 'privacidade'...» (Baker \& Jones, 1996: 79).

Relativamente à precisão e exactidão da informação que circula, a investigação revela que esta é, na sua maior parte, verdadeira. Tendemos a pensar que a ugrapevine» não é muito fidedigna, porque os erros deste tipo de informação têm efeitos muito marcantes, sendo, portanto, facilmente memorizáveis. Para além disso, basta que uma parte da informação seja incorrecta, para tornar toda a mensagem inexacta. Um outro factor que contribui para as diferenças de interpretação é o facto de, na maior parte das vezes, a informação transmitida ser incompleta. Ou seja, «embora a 'grapevine' tenha a tendência para transmitir a verdade, raramente transmite toda a verdade» (Newstrom \& Davis, 1997: 77). Perante isto, Newstrom \& Davis concluem que, no total, a 'grapevine' produz mais informação incorrecta do que aquela que seríamos levados a crer, se tivéssemos somente em conta a informação totalmente errada.

Este processo de comunicação informal torna-se assim indispensável, na medida em que transmite aos gestores muito feedback acerca dos elementos da organização e dos seus problemas. Por outro lado, pode também ajudar a «traduzir» as ordens formais dos gestores em «linguagem dos empregados», o que ajudará a colmatar as falhas comunicativas dos primeiros. Noutras situações, a "grapevine» também acaba por pôr a cir- 
cular informaçōes que o sistema formal de comunicação não quer assumir e, propositadamente, não diz. Sendo flexível e pessoal, espalha a informação mais depressa e penetra nas áreas da organização consideradas as mais seguras, fruto da sua capacidade de "cortar caminho» pelas linhas da estrutura organizacional, lidando directamente com as pessoas «bem colocadas» - acaba, assim, por ser uma fonte de comunicação confidencial.

A "grapevine» apresenta algumas consequências favoráveis e outras menos favoráveis. No entanto, a verdade é que a organização terá que saber aproveitar os seus aspectos mais positivos e saber lidar com os menos positivos, o que implica a compreensão, por parte dos gestores, dos processos que gerem esta rede informal, o conhecimento dos seus líderes e elementos activos e do tipo de informação que aí circula.

Muitos gestores já se deram conta desta necessidade, e alguns vão mesmo mais longe, tentando influenciar este processo de diversas maneiras. Uma das possibilidades poderá ser «deixar verter informação para a 'grapevine' para que nela passe a circular informação o mais correcta possivel» (Newstrom \& Davis, 1997: 77). Outros gestores tentam mesmo identificar as redes a que pertencem os elementos da organização. Conhecendo os seus contactos internos e externos, podem utilizar a "grapevine» como uma vantagem para a organização, partilhando determinada informação com as "pessoas-chave». Para além disso, a gestão deverá observar e avaliar a comunicação informal nas organizações e, quando necessário, clarificá-la através dos canais formais. Retomaremos este assunto mais adiante, quando nos referirmos às estratégias de prevenção dos rumores nas organizações.

Uma prática desenvolvida nos últimos anos que reflecte todo este tipo de esforços é o «management by walking around» (MBWA), já adoptado por grandes organizações como a IBM. Trata-se de uma técnica que implica que o gestor percorra a companhia, de maneira a que os elementos dos diferentes níveis e departamentos tenham oportunidade de fazer sugestōes ou críticas. Baker \& Jones, no entanto, apontam alguns riscos inerentes a este tipo de "gestão de porta aberta» (Baker \& Jones, 1996: 80), nomeadamente o facto de os gestores poderem ficar numa situação vulnerável, face a elementos da organização que se aproveitam da situação de contacto directo para exercer pressões e influência, numa tentativa de satisfazer os seus «comportamentos baseados em necessidades».

Uma outra perspectiva que podemos referir é a de Luthans (1995). Na sua opinião, a incapacidade das estruturas clássicas em corresponder às necessidades de comunicação interactiva nas organizações acaba por fazer emergir grupos informais para preencher esse vazio. Embora este sistema de comunicação informal, possa ser utilizado para espalhar falsos rumores ou informação destrutiva, também é verdade que é um suplemento dos canais formais, e muito eficiente, já que consegue, com muita rapidez, 
espalhar informação pertinente e importante para a prossecução dos objectivos e missão da empresa.

O que determina, em grande parte, a sua influência positiva ou negativa para a empresa são os objectivos da pessoa que comunica, já que este sistema informal tem uma "orientação altamente pessoal», podendo estes «objectivos pessoais ser ou não compatíveis com os objectivos da organização» (Luthans, 1995: 435). O grau de compatibilidade que exista terá um grande impacte no efeito que a "grapevine» exerce na organização.

Segundo Luthans (1995), embora a velocidade de funcionamento deste sistema informal dificulte o controlo de rumores por parte da gestão, também pode ser uma vantagem, já que a informação importante, relevante e que exige uma reacção rápida, tende a correr muito mais rapidamente neste sistema personalizado e directo do que através dos canais formais.

Também Robbins (1996) considera importantes as redes de comunicação informal que se distinguem dos mecanismos formais, que são tipicamente verticais, seguem a cadeia de autoridade e são o suporte para a informação relacionada com o desempenho na organização. Já as redes informais ...

«...movem-se livremente em qualquer direcção, escapam aos níveis de autoridade e procuram, ao mesmo tempo, satisfazer as necessidades sociais dos membros de grupo e facilitar o desempenho das tarefas» (Robbins, 1996: 316).

Este autor atribui à "grapevine» três características essenciais: não é controlada pela gestão; é percebida pela maior parte dos elementos da organização como sendo mais credível que os comunicados oficiais emitidos pela gestão de topo; e, finalmente, na maior parte das vezes, é utilizada para servir os interesses próprios dos que dela fazem parte.

A partir do que vimos até agora, apercebemo-nos de que, embora a preocupação com a comunicação interna informal das organizações tenha vindo a crescer, suscitando mesmo trabalhos de investigação, há ainda um longo caminho a percorrer até que o seu interesse e valor sejam plenamente assumidos pelos gestores e as suas potencialidades sejam verdadeiramente aproveitadas. Muitos dos receios e hesitações advêm certamente dos rumores que nela se cruzam e do carácter manipulatório, não ético e da ideia de falsidade a que estão associados, muitas vezes legitimamente.

\section{A partir da "Lei Básica»: algumas dimensões da «teoria do rumor»}

Criado e transmitido na 'grapevine', o rumor é ainda olhado com bastante desconfiança pelos gestores, o que não é surpreendente se tivermos 
em conta os efeitos devastadores que poderá ter numa organização. No entanto, a investigação sobre este tema tem contribuído para melhor compreender o seu funcionamento, dando também pistas importantes para o seu controlo.

Até aqui, referimo-nos à «grapevine», o sistema de comunicação informal interno que define e organiza os fluxos de informação entre os elementos de uma organização. Trata-se do suporte ou do meio através do qual circulam, entre outra informação, os rumores, como veremos de seguida. Não raras vezes, vemos os dois conceitos - "grapevine» e rumor usados indistintamente, o que não é estranho se tivermos em conta que um (rumor) é parte integrante do outro («grapevine»), o que faz com que tenham características semelhantes. No entanto, esta é uma perspectiva que não adoptamos, já que, na nossa opinião, nem toda a comunicação informal terá que se transformar em rumor, devendo a "grapevine» ser antes entendida enquanto suporte ou rede através da qual circula todo o tipo de comunicação informal, incluindo o rumor.

As primeiras investigações empíricas sobre rumores foram desenvolvidas por G. Allport, L. Postman e R. Knapp, durante a «Segunda Guerra Mundial», a pedido do Departamento de Defesa dos Estados Unidos da América, com o objectivo de controlar os inúmeros rumores que corriam acerca da situação e posição exacta dos aliados nas frentes japonesa e europeia. A falta de conhecimentos precisos, motivada pelo segredo militar, deixava o público sem qualquer informação ou fornecia apenas ideias muito vagas, surgindo assim a necessidade de completar este vazio, através da criação de rumores (Kapferer, 1990; Rosnow, 1991).

Segundo Gordon W. Allport e Leo Postman (cit. por Andrade, 1993: 111; cit. por Rosnow, 1991: 485), o rumor é a «exposição de um assunto destinada a ser acreditada, que passa de pessoa para pessoa, geralmente na forma oral e sem meios comprobatórios para assegurar a sua veracidade». Coube-lhes também a enunciação da chamada «Lei Básica do Rumor», a partir das investigações de Douglas McGregor, nos anos 30, segundo a qual terá que haver um ambiente propício à criação e disseminação de rumores: «... em primeiro lugar, o tema da história tem que ter alguma importância para quem fala e quem ouve; e, em segundo lugar, os factos verdadeiros terão que estar envolvidos por alguma ambiguidade» (Allport e Postman, cit, por Rosnow, 1991: 485). As concepções destes investigadores têm sido, ao longo dos anos, retomadas, testadas empiricamente e aperfeiçoadas, como veremos em seguida.

Rosnow define os rumores como...

«... comunicações públicas que reflectem hipóteses privadas acerca do funcionamento do mundo. Enriquecido por alegações ou atributos base- 
ados em provas circunstanciais, são tentativas de dar sentido a situações incertas.... O rumor é, ao mesmo tempo, um barómetro das tensões na comunidade e, às vezes, uma forma de prever comportamentos» (Rosnow, 1988: 13).

O contexto da criação e disseminação dos rumores assume assim uma importância fundamental, já que podemos encarar este processo como uma maneira de explicar ou de dar sentido às mudanças na comunidade ou organização e às suas consequências para os indivíduos: "este processo extrai sentido do contexto em que situa e também lhe dá sentido» (Rosnow, 1988: 14).

Podemos considerar que há duas grandes perspectivas de abordagem da natureza da disseminação dos rumores: a sociológica e a psicológica. A primeira, que analisa a rumor ao nível das acções colectivas, tem como principal representante Shibutani, que defende que «... a construção do rumor é uma forma de promulgar novos esquemas de coordenação quando passamos por grandes mudanças na vida...» (Shibutani, cit. por Rosnow, 1988). Ou seja, quando detectamos descoordenação num sistema, ficamos apreensivos e vamos procurar ouvir a opinião dos outros e obter o seu apoio. Assim, a criação de rumores permite-nos regular as nossas expectativas mútuas e os nossos comportamentos.

Uma outra perspectiva, a psicológica, analisa o rumor ao nível das necessidades individuais e tem como principais representantes Carl Jung e Allport \& Postman, já anteriormente referidos. Jung, que propõe uma interpretação psicoanalítica deste fenómeno, fala de dois tipos de rumores: visionários e ordinários. Se para a disseminação de rumores ordinários basta a curiosidade popular, no caso dos rumores visionários verificam-se as condiçōes de ansiedade e incerteza, funcionando como "prefigurações psíquicas subjectivas... são expressos sob a forma de visões, ou melhor, devem a sua existência a visões primordiais e mantêm-se vivos através dessas visões» (Jung, cit. por Rosnow, 1988: 16).

Um dos autores que retomou as concepções de Allport \& Postman e que as tem enriquecido e testado empiricamente é Rosnow, procurando fazer a síntese entre as concepções sociológica e psicológica. Defende que, para além da importância e ambiguidade, características apontadas pela «Lei Básica", há outras variáveis que influenciam as origens e perpetuação dos rumores. Rosnow considera assim a influência de quatro variáveis que afectam e podem prever a criação e transmissão de rumores. São elas: incerteza generalizada, ansiedade pessoal, credulidade e envolvimento relevante para os resultados («outcome-relevant involvement») (Rosnow, 1991: 485).

Em alternativa à «ambiguidade» de Allport \& Postman, Rosnow propõe a noção de «incerteza generalizada». Embora também considere que o estado de incerteza seja originado por acontecimentos problemáticos e instáveis, Rosnow insiste num estado de «suspensão de descrença» que 
caracteriza a relação entre os eventos e as pessoas que os percepcionam, estado esse que se «espalha» e generaliza a todo o indivíduo e ao contexto organizacional em que se possa inserir.

Quanto ao «envolvimento relevante para os resultados», é uma variável alternativa à «importância» de Allport \& Postman e traduz o pressuposto de que a relevância de um acontecimento e o envolvimento que suscitam são factores moderadores do processo de criação e disseminação de rumores. Rosnow (1991) defende que os indivíduos tendem a examinar menos criticamente as informações que não lhes suscitam grande envolvimento, embora haja autores que apontam para uma relação inversa: «quando há um grande envolvimento pessoal, a crítica é suspensa» (Sinha, cit. por Rosnow, 1991: 487).

Já a terceira variável, «ansiedade pessoal», não tem qualquer ligação directa com a «Lei Básica» e traduz um estado afectivo desencadeado ou associado à apreensão dos resultados iminentes e potencialmente negativos de determinado acontecimento.

Finalmente, temos a "credulidade» ou confiança no rumor, uma variável que se pode revelar importante, na medida em que, por vezes, haverá a tendência para transmitirmos unicamente as informações em que acreditamos (Rosnow, 1991), uma relação que não é, no entanto, absoluta, como veremos mais adiante.

Outros autores têm trabalhado e realizado estudos empíricos a partir destas variáveis, o que tem contribuído para um melhor conhecimento dos factores que propiciam o desenvolvimento dos rumores. Vejamos algumas dessas contribuições.

Difonzo, Bordia \& Rosnow definem o rumor como...

«... informação não verificada, geralmente com um interesse localizado, destinada primeiramente à crença ... os rumores são proposições ou alegações coloridas por várias sombras de dúvidas, porque não são acompanhadas de provas que as corroborem» (1994: 50).

A não existência de prova é o que, na opinião dos autores, distingue os rumores das notícias já que ambos explicam acontecimentos importantes e referem-se, de maneira positiva ou negativa, a pessoas ou acontecimentos. Para além desta característica de não confirmação, apontam o facto de os rumores nascerem de interesses colectivos, um aspecto que voltaremos a retomar mais adiante, quando nos referirmos concretamente aos ambientes organizacionais. Uma terceira característica definidora dos rumores é o facto de se destinarem à crença de quem os ouve, em situações de falta de informação credível, o que os distingue das "coscuvilhices», destinadas antes de mais a «entreter». 
A distinçāo entre rumor e coscuvilhice é também referida por Rosnow, a partir das palavras de Orrin Klapp:

\begin{abstract}
"A coscuvilhice é um tipo de informação interna e restringe-se à pequena comunidade ou grupo primário, enquanto que o rumor provém da sociedade mais abrangente, o mundo exterior. A coscuvilhice tem um enfoque íntimo e pessoal, enquanto que o rumor é impessoal e relata acções de estranhos. A coscuvilhice presta-se à 'conversa'; há o sentido de uma relação entre quem fala e quem ouve que ajuda a tornar a informação interessante; pelo contrário, o interesse do rumor provém de uma urgência externa, da possível importância de eventos remotos. No caso da coscuvilhice, há um grande consenso entre os participantes, porque pertencem à mesma comunidade, sabem e têm muitas coisas em comum, enquanto que no caso dos participantes no rumor há um baixo consenso, maior heterogeneidade nas opiniões e maior ignorância relativamente ao acontecimento partilhado" (Klapp, cit por Rosnow, 1988: 14).
\end{abstract}

Difonzo, Bordia \& Rosnow consideram que a generalidade dos rumores segue três fases de desenvolvimento: "geração", "avaliação" e "disseminação». Na primeira fase, a da geração do rumor, os indivíduos desenvolvem uma "susceptibilidade ao rumor" (Difonzo, Bordia \& Rosnow, 1994: 52) e são motivados a receber ou transmitir informações, o que depende de uma "combinação óptima de incerteza e ansiedade" (idem).

A incerteza pode ser definida como «o estado psicológico que se instala quando ocorrem eventos inexplicados» (idem). Trata-se de uma situação ambígua, em os acontecimentos são "cognitivamente obscuros" ou nãoestruturados e não podem ser imediatamente percebidos, porque lhes falta um contexto. Isto produz uma sensação de desconforto e insegurança, provocada pela imprevisibilidade dos efeitos dos acontecimentos em questão. Os rumores surgem assim como explicações que dão uma estrutura e contextualizam acontecimentos ambíguos.

Para além da incerteza, a geração de rumores exige que se verifique uma outra condição: a ansiedade, ou seja "o medo que ocorram acontecimentos negativos ou que não ocorram acontecimentos positivos» (Difonzo, Bordia \& Rosnow, 1994: 53). Os resultados da investigação apontam este factor como estando fortemente associado à transmissão de rumores. Aliás, parece lógico que a transmissão de rumores alivie a ansiedade, já que é uma forma de aferir a veracidade da informação e, ao mesmo tempo, ganhar algum controlo sobre um possível acontecimento negativo. Uma forma de avaliar a ansiedade provocada por um acontecimento é a análise da linguagem e tom utilizados para os descrever.

Gerado o rumor, segue-se a fase de avaliação da sua veracidade, uma condição importante para a decisão de o transmitir, já que a transmissão de informações falsas poderá acarretar penalizações (Difonzo, Bordia \& 
Rosnow, 1994; Rosnow, 1991). Ao considerarmos o processo de avaliação da veracidade de uma mensagem, há, logo à partida, que ter em conta que...

«... quanto mais uma história concorde com o conhecimento convencional ou com formas de pensar e pressupostos facilmente evocáveis e 'disponíveis', mais facilmente será vista como uma história provavelmente verdadeira" (Difonzo, Bordia \& Rosnow ,1994: 53).

Os autores destacam todavia dois aspectos essenciais deste processo de avaliação da veracidade das mensagens: por um lado, há que ter em conta que as cognições dos indivíduos podem ser teoricamente categorizadas de acordo com a sua acessibilidade (a facilidade com que «nos vêm à cabeça»); por outro lado, os rumores são classificados ao longo de um continuum probabilístico que vai do «muito provavelmente verdade» ao "muito improvavelmente verdade".

Relativamente à acessibilidade das cognições e pensamentos, temos também que ter em conta que podem agir no sentido de modificar os pressupostos do rumor para que se adequem melhor aos nossos quadros mentais, ou seja, de alguma forma «modulam» a forma como ouvimos a informação (Difonzo, Bordia \& Rosnow, 1994; Gilbert, Tafarodi \& Malone, 1993). Isto porque teremos tendência a acreditar mais facilmente num rumor que tenha sujacente pressupostos e formas de ver que nos sejam familiares, da mesma forma que estamos mais atentos a acontecimentos que tendam a validar e verificar o rumor. Rosnow refere-se mesmo a uma resistência dos indivíduos perante provas que possam invalidar as suas ideias preconcebidas, um estado que classifica como «suspensão de descrença» (Rosnow, 1988: 15), ao qual já nos referimos anteriormente.

Um factor extremamente importante quando se classifica uma informação no "continuum da veracidade» é a "credulidade» dos receptores, uma das características mais perceptíveis (Difonzo, Bordia \& Rosnow, 1994: 54). Isto implica que um indivíduo não tenha que acreditar totalmente num rumor para o transmitir.

Gilbert, Tafarodi \& Malone, ao investigarem o processo de crença em mensagens e afirmações, chamam a atenção para o facto de as pessoas terem...

"... tendência para acreditar naquilo que não devem... Depois de estas crenças estarem formadas, as pessoas têm uma dificuldade considerável em desfazê-las... mais ainda, há diversos estudos que sugerem que, em certas circunstâncias, as pessoas acreditam em afirmações que estão explicitamente 'etiquetadas' de falsas» (Gilbert, Tafarodi \& Malone, 1993: 222).

Dadas as limitaçôes humanas para avaliar a total veracidade de uma informação, teremos, muitas vezes, que nos contentar com uma «quase certeza», que cremos ser suficiente para aferir a qualidade de toda a infor- 
mação, atribuindo, desta forma, qualquer discrepância ao acaso ou a factores que não conhecemos.

Temos, finalmente, a última fase, a da disseminação do rumor. Cumpridas as condições anteriormente descritas, o rumor espalha-se e a crença reforça-se, particularmente através de dois mecanismos: a repetição e o tempo (Difonzo, Bordia \& Rosnow ,1994: 54; Gilbert, Tafarodi \& Malone, 1993: 222). Por um lado, a repetição reforça a crença. Só o facto de ouvirmos uma informação muitas vezes aumenta a nossa segurança na sua veracidade. Por outro lado, à medida que um rumor circula, dá-se um processo de mutação que o vai tornando mais plausível, um refinamento da informação, de acordo com aquilo que o transmissor acredita ser verdade. Daí que o tempo surja como um factor determinante no combate aos rumores, já que uma intervenção atempada e um corte na circulação do rumor vão contribuir para o decréscimo da sua credibilidade.

Marín define o rumor como «... informação vaga e confusa, procedente de fontes não claramente identificadas, que corre através dos canais informais, dando lugar a um conhecimento generalizado" (1997: 186). Desta definição salientamos a importância atribuída às fontes de informação ou "procedência do rumor», que este autor considera extremamente difíceis de identificar. Por outro lado, aponta para a existência e para o papel de "posições-chave» na difusão dos rumores, fruto da posição central que ocupam na organização informal, o que vai de encontro às concepções que referimos anteriormente quando descrevemos o funcionamento da "grapevine».

Ao contrário da generalidade dos autores, Marín salienta as vantagens que podem resultar da circulação de rumores nas organizaçōes e procura mostrar a necessidade de promover a complementaridade e interdependência entre os sistemas formal e informal:

"Contrariamente à crença popular, um rumor é um canal de comunicação muito poderoso e potencialmente útil na vida organizacional. A informação disseminada através do rumor viaja com extrema rapidez pela organização.... A rede de comunicação do rumor caracteriza-se por ser como uma cadeia de comunicação, através da qual as mensagens são distribuídas a um grupo de membros da organização, em vez de a uma só pessoa, acelerando a disseminação da informação ao maximizar o tamanho das audiências da mensagem informal» (Marín, 1997: 187).

A problemática das fontes de informação é um tema fundamental no estudo do rumor, e tem suscitado a atenção, não só de Kapferer (1987) ou Marín (1997), mas de outros autores como Andrade (1993). Segundo este autor, o rumor origina-se como consequência de falhas no sistema de comunicações, pela circulação de diferentes versões sobre um mesmo assunto $e$ por falta de confiança na fonte de informação. 
Andrade (1993) cita um estudo empírico realizado por Holand e Weiss, investigadores da Universidade de Yale, conduzido com o objectivo de avaliar a credibilidade atribuída às fontes de informação. A experiência foi realizada a partir de dois tipos de comunicadores: de alta e baixa credibilidade. Foram distribuídos questionários aos alunos imediatamente a seguir e um mês depois das comunicações, que versaram sobre quatro tópicos diferentes. De acordo com os resultados obtidos pela comparação das respostas, 30 dias depois tinham praticamente desaparecido as diferenças nas percentagens das respostas entre as fontes de alta e baixa credibilidade, tendo os investigadores retirado as seguintes conclusões: o esquecimento dos indivíduos, passado um mês, sobre a fonte da informação apresentada; a queda da credibilidade do indivíduo em relação à fonte em que acreditara e consequente tendência à modificação do seu ponto de vista na direcção da opinião contrária.

Este estudo poderia indicar que a fonte não influencia consideravelmente o percurso do rumor e a opinião dos ouvintes, uma conclusão que não é partilhada por autores como Kapferrer $(1987,1990)$ que atribui uma grande importância às fontes, especialmente na comunicação de desmentidos.

As investigações acerca dos rumores e boatos têm levado também a tentativas de elaboração de algumas tipologias, de entre as quais citaremos apenas três. Andrade divide os rumores em não intencionais e intencionais, sendo estes últimos «dirigidos com um fim determinado e ... com importantes objectivos emocionais» (1993: 113).

Rosnow refere uma investigação conduzida por Robert Knapp, durante a «Segunda Guerra Mundial», cujos resultados deram origem a uma tipologia. Numa análise de mil boatos recolhidos nos EUA, foi obtida a seguinte classificação, em três grandes categorias: «rumores sobre fantasias positivas» (menos de 4\%); «rumores de medo» (um terço); «rumores de agressão» (a maior parte) (Knapp, cit. por Rosnow, 1988: 17, 18).

Newstrom \& Davis (1997) identificam três tipos diferentes de rumores: alguns são «históricos e explanatórios» e tentam dar sentido à informação a partir de acontecimentos anteriores; outros são mais espontâneos e «orientados para a acção» e surgem a partir de tentativas para alterar o estado vigente; ocasionalmente, os rumores podem também ser «negativos», criando fracturas nos grupos, mas também "positivos», daí que, condenar à partida uma informação só porque foi recebida com o estatuto de rumor seja um atitude completamente errada.

A partir do que expusemos relativamente às características e fases de evolução dos rumores, está aberto o caminho para conceber estratégias que o previnam e, quando necessário, o neutralizem em ambientes organizacionais. 


\section{O rumor nas organizações: principais características e funções. Estratégias de prevenção e controlo.}

Embora as definições que podemos encontrar na bibliografia não vejam o rumor da mesma perspectiva, parecem estar de acordo quanto a algumas características básicas deste fenómeno de comunicação: é uma mensagem construída acerca de um assunto importante para os elementos da organização/comunidade, numa situação de falta de informação e de ansiedade; é geralmente, mas não necessariamente, transmitido na forma oral; a sua propagação é rápida e a sua credibilidade difícil de refutar; finalmente, há um certo acordo em relação à importância do papel desempenhado pela fonte de informação, enquanto factor de credibilidade, logo de aceitação, do rumor, embora, a partir de determinado nível de difusão, a identidade desta fonte inicial seja difícil de comprovar.

Na secção anterior, procurámos dar um breve panorama das principais questões debatidas no estudo do rumor. Para isso, destacámos algumas definições, características, estímulos e moderadores que intervêm no fenómeno de criação e disseminação dos rumores, recorrendo às conclusões e estudos empíricos de alguns autores incontornáveis quando tratamos esta problemática.

Tudo isto funciona como um enquadramento ou estrutura para podermos agora considerar o rumor em contexto organizacional, embora tenhamos já feito algumas referências à dinâmica da comunicação nas organizações. Iremos agora centrar-nos nas funções e características dos rumores organizacionais, bem como nas estratégias para os prevenir e controlar.

Segundo Robbins (1996: 320), os rumores cumprem quatro objectivos principais nas organizações: estruturar e reduzir a ansiedade; dar sentido a informação limitada ou fragmentada; servir como veículo para organizar os elementos de um grupo, e possíveis «outsiders», em coligaçōes; e, finalmente, para assinalar o estatuto ou poder do emissor. $\mathrm{O}$ rumor como meio de apropriação de poder é também referido por Lehnisch quando diz que "ter informação é ter poder" (1988: 60). Logo, o «iniciador» de um rumor, ao mostrar que tem acesso a informaçāo, procura garantir uma posiçāo de supremacia e controlo sobre os restantes elementos da organização. Este autor considera ainda que há dois «temas predilectos» em torno dos quais se criam os rumores: a questão da liberdade no interior da empresa (mecanismos de controlo da gestão) e os favoritismos.

Para além dos objectivos anteriormente enunciados, Lehnisch atribui aos rumores uma outra função algo original e terapêutica:

«... ao nível da comunicação organizacional, os rumores permitem suportar melhor uma rotina que pode desmotivar muitas pessoas. É uma forma de suportar melhor o longo rio tranquilo que $e ́$ a vida diária de uma instituição» (Lehnisch, 1988: 61). 
Como vimos anteriormente, os rumores tendem a surgir como uma forma de reagir a situações que são importantes para nós, mas ambíguas e criadoras de ansiedade. Daí que, nas grandes organizações, onde o segredo e a competição são muito mais fortes, os rumores tendam a surgir com maior frequência, persistindo até que as expectativas que lhes deram origem sejam cumpridas. Newstrom \& Davis (1997: 79) consideram que os rumores irão reflectir os interesses e ambiguidades de cada um dos elementos da cadeia de propagação (filtragem), o que faz com que seja sucessivamente alterado.

Tal como referimos anteriormente, Difonzo, Bordia \& Rosnow apontam como uma das características dos rumores o facto de resultarem de «preocupações colectivas» (Difonzo, Bordia \& Rosnow, 1994: 50), um aspecto importante quando falamos de rumores em organizações. Estes autores propõem uma lista de "subclasses de rumores organizacionais", elaborada a partir de uma investigação que implicou a realização de entrevistas em profundidade a gestores de nove companhias dos EUA e Índia, acerca da forma como estes gestores confrontavam os rumores nas suas organizações.

Estabelecendo uma relação entre o tipo de rumor e os interesses colectivos a ele associados, podemos dizer que: os «rumores sobre o abandono da empresa", "segurança no trabalho» e "qualidade do trabalho» têm raízes nas preocupações e ambiguidades originadas por mudanças iminentes na política de gestão ou de pessoal; os «rumores sobre a carreira e hierarquia» são típicos de indivíduos que têm dúvidas e se sentem inseguros relativamente à sua posição na empresa e a possíveis promoções; os "rumores sobre erros que implicam custos financeiros» reflectem preocupaçōes sobre prejuízos causados por condutas negligentes; e, finalmente, os "rumores sobre preocupações dos consumidores» reflectem os receios dos consumidores relativamente a um produto ou serviço da empresa (Difonzo, Bordia \& Rosnow, 1994: 50, 51).

A gestão não consegue eliminar por completo os rumores, mas poderá minimizar as suas consequências negativas, ao limitar o seu alcance e impacte. Em torno da questão do controlo dos rumores, podemos organizar a literatura de acordo com duas ideias: alguns autores colocam a tónica na prevenção dos rumores (Baker \& Jones, 1996; Robbins, 1996; Marín, 1997; Lehnish, 1988) e outros preocupam-se também com a forma de lidar com as suas consequências (Newstrom \& Davis, 1997; Kapferrer, 1987, 1990; Difonzo, Bordia \& Rosnow, 1994; Rosnow, 1988, 1991).

Robbins (1996: 320) sugere quatro formas de prevenir o surgimento de rumores: anunciando as alturas em que serão tomadas decisões importantes; explicando as decisões e comportamentos que possam parecer inconsistentes ou secretos; enfatizando os aspectos positivos, bem como os negativos, das decisões actuais e de planos futuros; discutindo abertamente as piores possibilidades de resolução dos problemas. 
Lehnish (1988) considera inútil querer suprimir por completo os rumores e defende a necessidade de os gestores procurarem estar ao corrente da informação que circula nas organizações, o que poderá ser conseguido através do contacto com as bases, da circulação pela instituição, de uma "gestão de porta aberta». Segundo este autor, a melhor forma de reagir é a prevenção, o que implica que não haja resistência na partilha de informação (poder): é preciso explicar para evitar a criação de explicações alternativas.

Baker \& Jones (1996) propõem um conjunto de «estratégias organizacionais que podem ou evitar este comportamento no local de trabalho", de entre as quais destacamos algumas. Segundo estes autores, o factor que mais contribui para a criação da "grapevine de veneno" (Baker \& Jones, 1996: 84), a forma como caracterizam a rede de relações resultante dos "comportamentos baseados em necessidades", é a incapacidade de se definir e manter fronteiras legítimas nas organizações, de maneira a que os seus elementos não se sintam "obrigados» a participar em conversas informais.

Quanto às medidas a implementar, referimos apenas algumas das propostas destes autores: os gestores e restantes elementos da organização podem comprometer-se a quebrar a "cadeia de rumor», ouvindo as informações, mas evitando qualquer contributo verbal ou não verbal; podem também comprometer-se a ser honestos e imediatos nas suas comunicações, de maneira a criar e incentivar lealdade e confiança; os elementos da organização deverão encontrar um «confidente» fora do local de trabalho, com quem possam conversar de forma «saudável» sobre as suas preocupações laborais; e, finalmente, todos devem poder «dizer não», ou seja, a qualquer momento, deverá ser possível a todos os indivíduos recusarem-se a tomar parte de uma conversa que considerem inapropriada ou a iniciar relações informais de dependência e troca informativa com alguém dentro da organização (Baker \& Jones, 1996: 85).

Através destas medidas, as organizações poderão evitar «ser encurraladas em relações não saudáveis...», ao mesmo tempo que «... irá decrescer a necessidade de confiar na 'grapevine' como primeira fonte de informação...» (Baker \& Jones, 1996: 86).

Difonzo, Bordia \& Rosnow consideram que é possível e desejável que os gestores se preocupem com a prevenção de rumores "reduzindo as condições (incerteza e ansiedade) que tornam as pessoas susceptíveis a eles ou reduzindo a credulidade de potenciais participantes» (Difonzo, Bordia \& Rosnow, 1994: 55, 56, 57). As estratégias de prevenção propostas por estes autores envolvem três preocupações principais: reduzir a geração de rumores; reduzir a credulidade dos indivíduos e reduzir a disseminação dos rumores.

Para reduzir a criação de rumores, dever-se-á «explicar o inexplicado», minimizando assim a incerteza e ansiedade. A prevenção dos rumores 
conse-gue-se antecipando acontecimentos potencialmente geradores destes sentimentos, diminuindo também a credulidade, o que não é tarefa fácil, já que exige a presença de um observador atento e perspicaz, um «homem-radar» (Difonzo, Bordia \& Rosnow, 1994: 56).

Em ordem a reduzir a credulidade, o gestor poderá também dinamizar workshops onde se encoraje as pessoas a ter um olhar céptico sobre os rumores e onde os indivíduos possam aprender o que eles são, como se transmitem e quais as suas consequências. No entanto, para que uma medida desta natureza tenha sucesso, e não seja vista como uma forma de camuflar as injustiças e más condutas da gestão, tem que se verificar uma condição essencial: um clima de confiança. Desta maneira, reduz-se a credibilidade dos rumores prejudiciais e os indivíduos estão mais predispostos a interpretar acontecimentos ambíguos de uma forma menos drástica.

A importância da educação dos indivíduos, como forma de resistir a «falsas ideias» é igualmente referida por Gilbert, Tafarodi \& Malone (1993: 231).

Para reduzir a disseminação de rumores e os seus efeitos perversos (a repetição ao longo do tempo aumenta a ansiedade e incerteza) é essencial detectá-los antecipadamente. Difonzo, Bordia \& Rosnow propõem o recrutamento de um empregado de confiança que tome conhecimento dos rumores e os comunique rapidamente: «... o subordinado seria instruído a comunicar os rumores de forma a não prejudicar o emprego de ninguém. Isto não só é ético, como também é prático» (Difonzo, Bordia \& Rosnow, 1994: 57).

À semelhança destes autores, Marín também aponta como estratégia de prevenção a utilização de pessoas centrais e influentes na organização («homem-radar»):

«... a Direcçāo pode beneficiar das tendências dos líderes informais para disseminar informação, mantendo-os informados sobre os acontecimentos importantes e desenvolvendo boas relaçōes com eles. Ao proporcionar-lhes informação relativamente precisa sobre a organização, os directores podem ajudar a eliminar a propagação de rumores perigosos ou falsos... Mais ainda, a Direç̧ão pode obter informação ascendente relevante e feedback por parte dos líderes informais, que geralmente sabem muito acerca do que acontece diariamente na organização" (Marín, 1997: 187).

Desta forma, há maiores garantias de que circule pela organização informação útil e verdadeira, até porque é do interesse dos próprios líderes informais que isto aconteça:

«... Normalmente, os líderes informais nāo querem difundir mentiras, mas necessitam de informação precisa para manter o seu poder informal sobre outros membros da organização. Os rumores falsos são tăo peri- 
gosos para os líderes informais como para os demais, já que mentiras podem dinamitar a posição e poder do líder informal" (Marín, 1997: 187).

Newstrom \& Davis (1997), para além da prevenção dos rumores, apontam outros caminhos, em ordem a controlá-los, quando não podem ser evitados: refutá-lo com factos; lidar com eles rapidamente; utilizar mais frequentemente a comunicação frente-a-frente; recolher informações de fontes credíveis e, finalmente, tal como propõe Lehnisch, ouvir todos os rumores para perceber o que significam. O essencial é não ignorar os rumores nem descurar a "grapevine», simplesmente porque por ela passam algumas informaçōes incorrectas. A questão da refutação dos rumores tem conduzido as pesquisas de Kapferer (1987, 1990), nomeadamente o processo do «desmentido» ou «anti-boato», em torno da qual tem realizado vários estudos empíricos, com o objectivo de encontrar e avaliar as suas estratégias de elaboração e difusão, bem como as suas condições de funcionamento e eficácia.

Não sendo possível prevenir o surgimento e disseminação dos rumores, Difonzo, Bordia \& Rosnow propõem algumas «estratégias de neutralização». Uma primeira medida poderá ser simplesmente «ignorar os rumores impotentes» (Difonzo, Bordia \& Rosnow, 1994: 57), o que evita o fenómeno de repetição, mas não deixa de ser uma táctica um tanto falível. Isto porque é muito difícil ter garantias de que o que não é plausível para uma pessoa será visto da mesma forma por todas as outras, uma situação em que o «homem radar» poderá ser de grande utilidade. Esta medida é, pois, vista como um luxo ao qual muito poucos gestores se podem dar.

A partir do momento em que não seja possível ignorar o rumor e sejam colocadas questões à gestão, esta terá que tomar alguma medida: confirmar a sua percentagem de verdade para não dar azo a mistificações; recusar-se a comentar, o que, geralmente, induz mais incerteza e desconfiança; ou ainda comentá-lo, tentando ridicularizá-lo e colocando em causa a credibilidade da sua fonte, o que só resulta se se tratar de uma rumor fraco, numa situação de baixa incerteza e ansiedade.

Uma quarta estratégia é a da "refutação efectiva» (Difonzo, Bordia \& Rosnow, 1994: 58), a melhor forma de neutralizar rumores credíveis em ambientes susceptíveis. Reduz-se a segurança dos indivíduos no rumor, através de uma refutaçāo forte. Há que ter, no entanto, algum cuidado com os desmentidos, para que estes não façam aumentar a crença no rumor, "virando-se o feitiço contra o feiticeiro».

Para garantir a eficácia desta estratégia, há pois que tomar algumas precauções: os desmentidos têm que ser absolutamente verdadeiros; terá que haver consistência nas declarações da organização; terá que haver um extremo cuidado ao seleccionar o porta-voz da empresa; não se deve repetir o rumor na mensagem, para não potenciar o factor repetição; e, finalmente, 
o gestor poderá organizar uma espécie de «assembleia geral», na qual se coloque à disposição para responder a perguntas e esclarecer dúvidas, o que permitirá, eventualmente, prevenir o aparecimento de outros rumores, para além de aumentar a credibilidade do gestor e fazer diminuir a incerteza, ansiedade, credulidade e evitar a repetição do rumor (Difonzo, Bordia \& Rosnow, 1994: 59, 60).

O facto de o desmentido ser verdadeiro, para além de ser uma atitude ética e honesta, faz aumentar a reputação do gestor e cria uma clima de confiança. Um falso desmentido é facilmente descoberto e tem consequências desastrosas. Um desmentido verdadeiro favorecerá também a consistência das declarações, tal como a escolha do melhor porta-voz para a situação, um processo em que se deve procurar um equilíbrio entre a seriedade do rumor em questão e o nível hierárquico do potencial representante da organização. Tendencialmente, os níveis hierárquicos mais altos são considerados mais credíveis, mas não pode haver uma discrepância muito grande, sob pena de um porta-voz de um nível hierárquico muito elevado poder chamar a atenção para o rumor, tornando-o mais sério e aumentando a especulação.

Naturalmente que todos estes esforços serão vãos se a mensagem não for clara, simples e concisa, logo, memorizável. Todas estas medidas, se bem desenvolvidas e articuladas, farão diminuir a credulidade dos receptores.

Rosnow, para além da prevenção de rumores, também prevê estratégias para o seu controlo e gestão. Relativamente às medidas de prevenção, tal como outros autores, aponta para a necessidade de antecipar acontecimentos em que os níveis de ansiedade e incerteza possam favorecer a criação de rumores prejudiciais. São várias a medidas a tomar neste sentido: manter as linhas de comunicação abertas («rumor-lines»); dar às pessoas factos $\mathrm{e}$ informações úteis e verdadeiras sobre a vida organizacional, em ordem a manter a sua confiança; educar as pessoas no sentido de desenvolverem faculdades críticas que lhes permitam identificar os falsos rumores e as suas consequências destrutivas (Rosnow, 1988; 1991).

Falhando a estratégia de prevenção, é importante minimizar os efeitos do rumor, evitando a sua repetição; se necessário, e se for possível identificar a fonte do rumor, a organização deverá estar disposta a tomar medidas legais, que funcionem como exemplo para futuras situações (Rosnow, 1988; 1991).

Estas são as propostas de alguns autores para lidarmos com os rumores nas organizações, quer através da sua prevenção, quer por intermédio de estratégias de neutralização da sua disseminação e dos seus efeitos negativos. Apesar de tudo, os gestores nem sempre colocam em acção estes mecanismos e, na maioria das vezes, descuram esta dimensão comunicativa.

Os resultados de dois dos poucos estudos realizados em empresas portuguesas mostram como a comunicação informal é vista pelos nossos 
gestores. Trata-se de um estudo conduzido por Alexandra Tenera, engenheira e docente na Faculdade Nova de Lisboa, no âmbito da sua dissertação de mestrado (Tenera, 1998) e dos resultados de uma investigação levada a cabo por Paula do Espírito Santo (Espírito Santo, 1996) docente do Instituto Superior Técnico.

Embora os resultados não sejam exactamente os mesmos, permitem-nos destacar alguns aspectos genéricos: na maior parte das empresas, as questōes da comunicação interna são ainda tratadas pela administração e, só muito raramente, estão a cargo do Departamento de Recursos Humanos; na maioria dos casos, não há funcionários estritamente responsáveis pela comunicação interna, nem há orçamento próprio que, quando existe, é muito inferior aos gastos com o marketing externo; a maioria das organizações não avalia a eficácia da sua comunicação interna; a informação organizacional é veiculada principalmente através de placards informativos, memorandos, circulares e notas de serviço, embora existam alguns órgãos de imprensa empresarial e se utilizem outros meios; finalmente, o rumor não é reconhecido como meio de informação, mas admite-se o seu peso na comunicação interna informal e é visto como um excelente indicador da existência de problemas de comunicação interna.

Uma perspectiva, não menos interessante que as apontadas até agora, prende-se com uma visão do rumor enquanto um mecanismo de "anticensura" uma forma de prevenir "o controlo da informação e da palavra» (Kapferer, 1987), na medida em que...

«... o boato não é necessariamente falso: em contrapartida, é necessariamente não oficial. À margem, e por vezes em oposição, o boato contesta a realidade oficial propondo outras realidades.... A concepção negativa que associa o boato à falsidade é de ordem tecnológica; só é boa comunicação aquela que é controlada. $\mathrm{O}$ boato opõe um outro valor: só é boa a comunicação que for livre, mesmo que a sua credibilidade venha a ser prejudicada. Por outras palavras, os 'falsos' boatos constituem o preço a pagar pelos boatos com fundamento.... O boato volta a demostrar, se necessário, que todas as certezas são sociais: é verdade o que o grupo a que pertencemos considera como verdade. $O$ saber social assenta na fé a nāo na prova» (Kapferer, 1987: 244).

No entanto, para além desta concepção «libertadora» dos rumores nas organizações, consideramos imprescindível que o estudo deste fenómeno seja concretizado de forma tão rigorosa quanto possível, e que se possa fornecer a "prova» do importante papel dos rumores na comunicação informal, proporcionando novas definições, reflexões em torno de outras dimensões e tipologias e quadros teóricos mais alargados.

$\mathrm{O}$ facto de os rumores atravessarem toda a nossa vida, inclusivamente as áreas que menos esperaríamos, pode ser ilustrado com um exemplo do mundo jornalístico, um campo onde reinam valores como a verificação 
de fontes e a necessidade de sermos tão objectivos quanto possível. Quiroga (1999), investigou a função do jornal «El País» na construção da realidade durante a ditadura militar argentina, a partir de uma análise das fontes de informação utilizadas. Para isto, foram analisadas as unidades de informação referentes à Argentina, provenientes da Agência Efe (Buenos Aires), durante dois meses. Das 27 unidades de informação, 3 continham menções explícitas a rumores como fontes de informação, o que não deixa de ser significativo, mesmo tratando-se de tempos políticos conturbados, especialmente se considerarmos que houve 8 menções a outras agências informativas, o que traduz uma diferença muito pequena.

Embora a cadeia do rumor seja um fenómeno difícil de estudar empiricamente, pensamos que alguns dos obstáculos podem ser ultrapassados, nomeadamente o acompanhamento do processo de criação e disseminação, a relação interactiva entre os participantes e o registo fiel dos dados. Bordia \& Rosnow (1998) mostram um novo caminho através da CMC (Comunicação Mediada por Computador), com uma análise de conteúdo das mensagens individuais, relativas a um rumor surgido na Internet. Trata-se de uma possibilidade a explorar, numa tentativa de continuar a reflexão $\mathrm{e}$ estudo de um tema tão complexo quanto este.

\section{Conclusões, limitações e linhas de investigação a prosseguir}

A revisão teórica que propomos mostra que há ainda muito a fazer nesta área e que podemos aprofundar o estudo de algumas dimensões importantes: o valor dos rumores e da comunicação informal em situaçōes de mudança, devido à sua velocidade de propagação, ou quando é necessário transmitir más notícias; a credibilidade e multiplicidade das fontes de informação; uma possível adaptação e aplicação de alguns modelos de comunicação da Escola Processual (Fiske, 1993) a esta área, o que poderá contribuir para uma melhor compreensão deste fenómeno, nomeadamente através de conceitos como a "percepção" ou o "ruído"; o papel das novas tecnologias e os perigos decorrentes da sua aplicação pouco reflectida, negligenciando a comunicação interpessoal; a importância dos contextos na transmissão de informação; e ainda as dimensões de intencionalidade, poder, comportamento político e ética inerentes à proliferação de boatos e rumores.

Seria igualmente importante convocar o conceito de confiança, fundamental quando falamos de relacionamentos informais, bem como o papel da memória na construção e disseminação das mensagens, sob a forma de rumor.

O próprio trabalho que aqui trazemos é em si mesmo uma ilustração da grande dificuldade com que se depara a investigação sobre os rumores: 
a escassez de trabalhos empíricos. Um caminho para colmatar esta lacuna poderá ser o recurso à $\mathrm{CMC}$, numa era em que se vulgarizou a «grapevine electrónica».

Acima de tudo, importa que os gestores estejam atentos aos progressos que já foram feitos nesta área e transportem estes conhecimentos para as suas organizações, enfrentado os rumores e lidando com eles de forma a, tanto quanto possível, minorar os seus efeitos negativos e potenciar os resultados positivos que possam advir desta «livre circulação da palavra». 


\section{REFERÊNCIAS BIBLIOGRÁFICAS}

ANDRAdE, T. (1993). Para Entender Relaçōes Públicas (4." edição). São Paulo: Edições Loyola.

BAKER, J. S. \& MERRIL A. Jones (1996). The poison grapevine: how destructive are gossip and rumor in the workplace. Human Resource Development Quarterly, 7 (1).

Bordia, P. \& RalPh Rosnow (1998). Rumor rest stops on the information highway. Human Communication Research, 25 (2).

Difonzo, N., BORdiA, P. \& RALPH R. ROSNOW (1994). Reining in rumors. Organizational Dynamics, (Summer).

EsPíRITo SANTO, P. (1996). A comunicação interna nas maiores empresas portuguesas. Comunicaçāo Empresarial, 3.

FISke, J. (1993). Introdução ao Estudo da Comunicaçāo. Porto: Edições Asa.

Gilbert, D., Tafarodi, R. \& Patrick S. Malone (1993). You can't not believe everything you read. Journal of Personality and Social Psychology, 65 (2).

KAPFERER, J.-P. (1990). Le contrôle des rumeurs - expériences et refléxions sur le démenti. Communications, 52.

KAPFERER, J.-P. (1987). Boatos: o meio de comunicaçāo mais velho do mundo. Lisboa: Ediçōes Europa-América.

KrePS, G. (1990). Organizational Communication - Theory and Practice (2nd edition). New York: Longman.

Lehnisch, J. (1988). Maîtriser la Communication dans l'Entreprise. Paris: Éditions d'Organisation.

LrTtrejohn, S. (1982). Fundamentos Teóricos da Comunicação Humana. Rio de Janeiro: Zahar Editora.

Luthans. F. (1995). Organizational Behavior, (7th edition). New York: McGraw Hill.

Marín, A. (1997). La Comunicación en la Empresa y en las Organizaciones. Barcelona: Bosch Casa Editorial.

Newstrom, J. W. \& K. Davis (1997). Organizational Behavior: a Management Challenge (2nd edition). Fort Worth: The Dryden Press.

Quiroga, M. J. (1999). Las fuentes de información y la constucción de la realidad. Revista Latina de Comunicación Social, Ano III, 5 (2).

Roвbins, S. P. (1996). Organizational Behavior: concepts, controversies, applications (7th edition). Englewood Cliffs, NJ: Prentice-Hall.

Rosnow, R. (1991). Inside rumor: a personal journey. American Psychologist, 46 (5).

RosNow, R. (1988). Rumor as communication: a contextualist approach. Joumal of Communication, 38 (1).

TEnera, A. (1998). A comunicação como um elemento da qualidade total. Comunicaçāo Empresarial, 9.

THAYER, L. (1976). Comunicaçāo: Fundamentos e Sistemas. S. Paulo: Atlas. 